\title{
Traumatic Penile Amputation: A Case Report and Acute Management
}

\author{
Mehul S Patel, Drew Jensen and Stephen H Culp*
}

Department of Urology, University of Virginia, USA

\begin{abstract}
Traumatic penile amputation is a rare clinical situation. We report a case of self-inflicted penile amputation in a patient with psychosis and discuss the surgical management. Acute management largely entails stabilization in preparation for surgery, where options include replantation of the amputated penis versus closure of the remaining stump, depending on the viability of the penis. Although replantation is the best option, it is often not possible and thus closure of the wound is acceptable.
\end{abstract}

Keywords: Traumatic penile amputation; Genital mutilation

\section{Introduction}

Traumatic penile amputation is an uncommon surgical emergency with various etiologies. Frequently, the injury is self-inflicted by patients suffering from an acute psychotic episode [1]. However, the injury has also been described secondary to domestic violence, other criminal assaults, and accidental trauma [2-4]. Nonetheless, the incidence of traumatic penile amputation remains low, limiting our understanding mainly to case reports and reviews. Notably, the largest case series comes from Thailand which developed much of the early understanding of the injury and management [2]. During the late 1970s, there was an epidemic of penile amputations by wives of unfaithful husbands leading to the treatment of 18 cases at a single center, representing the largest series to date. Regardless of the etiology, penile amputation represents a surgical emergency that must be addressed quickly and efficiently in order to maximize functional outcomes.

\section{Clinical Case}

We report a 24 year old male with no known past medical history who presented to an outside emergency department with selfinflicted penile injury. The patient had a history of hearing voices for approximately 1 year without psychiatric evaluation. At the command of the voices, he used a sword to amputate the distal end of his penis, slightly proximal to the level of the glans. Hemostasis was achieved at the outside hospital with 5-0 Vicryl suture to the dorsal complex and a circumferential dressing. The amputated appendage was discarded en route by the patient and therefore unsalvageable. The patient arrived at our institution approximately 10-12 hours post injury. On arrival, the patient was hemodynamically stable. Physical exam was notable for transverse amputation of the glans with an adherent clot on the amputated tip. A secondary survey of the patient revealed no other injuries. Haldol $5 \mathrm{mg}$ was required for acute psychotic stabilization and sedation. The patient was taken immediately to the operating room for debridement, washout, and hemostasis. The decision was made to close the remaining stump since the amputated appendage was unavailable for replantation.

Under general anesthesia, the patient was placed in the supine position and prepped and draped in sterile fashion. A penrose tourniquet was placed at the base of the shaft. Hemostasis of the cavernosal arteries was then obtained with 3-0 Vicryl suture bilaterally. The cavernosa were sutured to the intracrural septum with 3-0 Vicryl. The urethra was spatulated ventrally and skin flaps were created laterally. The urethra was then brought out to the skin with
4-0 Monocryl suture. The skin was subsequently closed with running 3-0 Chromic after obtaining adequate hemostasis with 4-0 Monocryl suture and Bovie electrocautery. For post-operative pain control, a penile block was performed with $0.5 \%$ Marcaine without epinephrine. A Foley catheter was placed along with a compressive circumferential dressing. After acute recovery, the patient was transferred to the psychiatric floor for further management.

The patient's post-operative course was unremarkable from a surgical standpoint with minimal drainage and penile edema. On post-operative day 2, the Foley catheter was removed and the dressing was taken down. On post-operative day 7 , the patient had recovered well and was voiding effectively, but remained institutionalized for psychiatric care. On post-operative day 20 , the patient was deemed stable from a psychiatric standpoint for discharge.

\section{Discussion}

Traumatic penile amputation represents a rare surgical emergency that must be addressed quickly. With the potential for significant hemorrhage, the patient may require aggressive fluid resuscitation and blood transfusion [5]. During the secondary survey, it is important to look for any additional injuries, especially in the case of self-inflicted amputation by a psychotic patient. The possibility of drugs and/or alcohol intoxication or overdose should also be considered during initial stabilization [1]. A subsequent thorough history is essential to determine the nature of the injury. In an acutely psychotic patient, proper psychiatric evaluation is warranted for acute stabilization and post-operative treatment. During this time, the patient should be prepared for surgery.

Surgical management options include surgical replantation of the appendage or closure of the remaining stump depending on the viability of the amputated penis. A third option involves phallic replacement or reconstruction, but this is best reserved for after the acute injury has healed [6].

*Corresponding author: Stephen H Culp, Department of Urology, University of Virginia, USA, Tel: 434-243-9325; Fax: 434-982-3652; E-mail: shc5e@virginia.edu

Received June 17, 2014; Accepted September 10, 2014; Published September 17,2014

Citation: Patel MS, Jensen D, Culp SH (2014) Traumatic Penile Amputation: A Case Report and Acute Management. J Trauma Treat 3: 210. doi:10.4172/21671222.1000210

Copyright: ( 2014 Patel MS, et al . This is an open-access article distributed under the terms of the Creative Commons Attribution License, which permits unrestricted use, distribution, and reproduction in any medium, provided the original author and source are credited. 
Surgical replantation is the preferred option because it offers the patient the best chance to return to normal function. One major limiting factor to replantation is the viability of the penis. Replantation should be performed as soon as possible in order to minimize tissue ischemic injury. In addition, the degree of ischemia can be decreased by hypothermic cooling of the penis with the double bag technique [7]. The amputated penis should be wrapped in saline-soaked gauze and placed in a sterile bag, and the bag should be placed into a second bag or container of ice and water. With hypothermic ischemia, replantation has been successfully described in cases of 16 hours of ischemia [5]. Therefore, replantation has been encouraged up to 24 hours after the initial injury [7].

The first reported case of replantation dates back to 1929 when Ehrich reattached an amputated penis without consideration of any neurovascular structures [8]. Since then, many macrosurgical replantations have been reported with varying degrees of success, most notably from the case series from Thailand [2]. The first microsurgical approach was described in 1977 by Cohen et al. and Temai et al. $[9,10]$. After these initial cases, numerous other reports of successful replantation have followed. Jezior et al. examined 21 cases of microsurgical replantation [6]. In terms of erectile function, 15/19 patients reported normal erections while $4 / 19$ had decreased erections, the latter possibly confounded by new psychiatric medications. In terms of penile sensation, 14/17 patients reported normal sensation. The most common complication was mild skin necrosis, which occurred in 11 of 20 patients. Four of 20 patients were found to have urethral stricture. Because a microsurgical approach offers the best chance at return to normal function, it represents the standard of care for penile amputations, even if the patient must be transferred to higher level centers capable of such techniques.

Although replantation is gold standard, it is not always possible. Replantation requires an available and viable appendage. As in our presented case, the penis may not be recovered after the injury. Even with recovery, the penis must be viable, which entails limited ischemia time as well as structural integrity that would not compromise repair. If the double bag technique is not employed, the replantation time window is significantly limited. Additionally, some patients may not seek immediate medical attention, especially in the case of a psychotic patient [5]. Lastly, the expertise necessary for replantation may not be available at all centers, especially microsurgical techniques. In these cases, transfer to centers with these capabilities is encouraged, although this may extend the ischemia time considerably.

When replantation is not possible, completion of the partial penectomy with distal urethroplasty is appropriate. As with our patient, there may still be adequate shaft length to preserve voiding and possibly sexual function. The adequate length for proper function is unclear, but is likely minimal for voiding and variable for sexual function depending on each individual patient. Further research is necessary to investigate the frequency of replantation versus partial penectomy in these cases.
When the penis has been severed at the base or at a level of inadequate length, phalloplasty may be the best course of action. However, it is not performed acutely and should be reserved for once the initial trauma has healed [6]. This allows for a more thorough evaluation of the patient, including mental status, personal goals, and support system. Although this information would also be beneficial before replantation, the time sensitivity of the procedure is a limiting factor.

\section{Conclusion}

Traumatic penile amputation is a rare surgical emergency that requires immediate attention. Acute medical management includes hemodynamic stabilization, treatment of secondary wounds, and possible psychiatric treatment. Acute surgical exploration and debridement is necessary in all cases. Although replantation is the gold standard treatment, it is often not a viable option, in which case closure of the remaining stump is acceptable.

\section{References}

1. Aboseif S, Gomez R, McAninch JW (1993) Genital self-mutilation. J Urol 150 1143-1146.

2. Bhanganada K, Chayavatana T, Pongnumkul C, Tonmukayakul A Sakolsatayadorn P, et al. (1983) Surgical management of an epidemic of penile amputations in Siam. Am J Surg 146: 376-382.

3. Chou EK, Tai YT, Wu Cl, Lin MS, Chen HH, et al. (2008) Penile replantation, complication management, and technique refinement. Microsurgery 28: 153156 .

4. Riyach O, El Majdoub A, Tazi MF, El Ammari JE, El Fassi MJ, et al. (2014) Successful replantation of an amputated penis: a case report and review of the literature. J Med Case Rep 8: 125.

5. Wei FC, McKee NH, Huerta FJ, Robinette MA (1983) Microsurgical replantation of a completely amputated penis. Ann Plast Surg 10: 317-321.

6. Jezior JR, Brady JD, Schlossberg SM (2001) Management of penile amputation injuries. World J Surg 25: 1602-1609.

7. Chang AJ, Brandes SB (2013) Advances in diagnosis and management of genital injuries. Urol Clin North Am 40: 427-438.

8. Ehrich WS (1929) Two Unusual Penile Injuries. J. Urol. 21:239.

9. Cohen BE, May JW Jr, Daly JS, Young HH (1977) Successful clinical replantation of an amputated penis by microneurovascular repair. Case report. Plast Reconstr Surg 59: 276-280.

10. Tamai S, Nakamura Y, Motomiya $Y$ (1977) Microsurgical replantation of a completely amputated penis and scrotum: case report. Plast Reconstr Surg 60: 287-291. 